\title{
Mononuclear phagocyte intercellular crosstalk facilitates transmission of cell-targeted nanoformulated antiretroviral drugs to human brain endothelial cells
}

\author{
This article was published in the following Dove Press journal: \\ International Journal of Nanomedicine \\ 7 May 2012 \\ Number of times this article has been viewed
}

\author{
Georgette D Kanmogne' \\ Sangya Singh' \\ Upal Roy' \\ Xinming Liu' \\ JoEllyn McMillan' \\ Santhi Gorantla' \\ Shantanu Balkundi' \\ Nathan Smith' \\ Yazen Alnouti ${ }^{2}$ \\ Nagsen Gautam ${ }^{2}$ \\ You Zhou ${ }^{3}$ \\ Larisa Poluektova' \\ Alexander Kabanov ${ }^{2}$ \\ Tatiana Bronich ${ }^{2}$ \\ Howard E Gendelman' \\ 'Departments of Pharmacology and \\ Experimental Neuroscience, University \\ of Nebraska Medical Center, Omaha, \\ ${ }^{2}$ Department of Pharmaceutical \\ Sciences, University of Nebraska \\ Medical Center, Omaha, NE; ${ }^{3}$ Center \\ for Biotechnology, University of \\ Nebraska-Lincoln, Lincoln, NE, USA
}

Correspondence: Georgette D Kanmogne Department of Pharmacology and Experimental Neuroscience, University of Nebraska Medical Center, Omaha NE 68198-52 I5, USA

Tel +l 4025594084

Fax + I 4025598922

Email gkanmogne@unmc.edu

\begin{abstract}
Despite the successes of antiretroviral therapy (ART), HIV-associated neurocognitive disorders remain prevalent in infected people. This is due, in part, to incomplete ART penetration across the blood-brain barrier (BBB) and lymph nodes and to the establishment of viral sanctuaries within the central nervous system. In efforts to improve ART delivery, our laboratories developed a macrophage-carriage system for nanoformulated crystalline ART (nanoART) (atazanavir, ritonavir, indinavir, and efavirenz). We demonstrate that nanoART transfer from mononuclear phagocytes (MP) to human brain microvascular endothelial cells (HBMEC) can be realized through cell-to-cell contacts, which can facilitate drug passage across the BBB. Coculturing of donor MP containing nanoART with recipient HBMEC facilitates intercellular particle transfer. NanoART uptake was observed in up to 52\% of HBMEC with limited cytotoxicity. Folate coating of nanoART increased MP to HBMEC particle transfer by up to $77 \%$. To translate the cell assays into relevant animal models of disease, ritonavir and atazanavir nanoformulations were injected into HIV-1-infected NOD/scid- $\gamma_{c}^{\text {null }}$ mice reconstituted with human peripheral blood lymphocytes. Atazanavir and ritonavir levels in brains of mice treated with folate-coated nanoART were three- to four-fold higher than in mice treated with noncoated particles. This was associated with decreased viral load in the spleen and brain, and diminished brain CD11b-associated glial activation. We postulate that monocyte-macrophage transfer of nanoART to brain endothelial cells could facilitate drug entry into the brain.
\end{abstract}

Keywords: nanoART, folate, monocyte-endothelial cell interactions, blood-brain barrier, antiretroviral therapy, nanomedicine

\section{Introduction}

HIV enters the central nervous system (CNS) in the early stages of infection. Following sustained viral replication in brain mononuclear phagocytes (MP) (blood-borne macrophages and microglia) and progressive immune suppression, HIV incites glial inflammation and injures neurons (for recent reviews, see ${ }^{1,2}$ ). Such pathobiologic events result in behavioral, motor, and cognitive impairments that range from clinically asymptomatic to frank dementia, referred to as HIV-associated neurocognitive disorders (HAND). ${ }^{3,4}$

Despite the effectiveness of combination antiretroviral therapy (cART) in reducing morbidity and mortalities, HAND remain a highly prevalent comorbid condition. ${ }^{5}$ This may be due, in part, to the poor ART penetration into the CNS and continuance of the brain viral reservoir. ${ }^{6-9}$ Alternatively, HAND may be affected by neurotoxicities seen 
as a consequence of long-term therapies that penetrate the nervous system. ${ }^{10}$ Notably, ART drugs are often substrates for efflux transporters such as P-glycoproteins and multidrugresistant associated proteins present on brain endothelial cells. ${ }^{711,12}$ Thus, even when ART can reduce viral load in the periphery, productive HIV infection can continue in the CNS. Increasing ART penetration into the brain could help reduce the CNS viral load and diminish injury and death of neural cells. Most importantly, site-directed therapies, as developed through nanoformulated crystalline ART (nanoART), could reduce inherent ART toxicities.

A means to reduce the viral reservoir in the CNS while limiting toxicities is to increase brain- or region-specific ART access. This may occur by repackaging traditional antiretroviral medications into nanoART vectors to facilitate cell-based delivery of drug and, as such, improve ART pharmacokinetics and biodistribution. ${ }^{13}$ To this end, our prior works demonstrated limited cytotoxicity of nanoART to monocytes and macrophages ${ }^{14}$ and efficient macrophage uptake, distribution, and release of nanoART in both in vitro and animal models of human disease. ${ }^{15-17}$ Macrophage drug carriers were able to deliver ART to the same tissue sites where active HIV-1 replication ensues. ${ }^{15-21}$ However, what remained unanswered was the effect of nanoART on specific drug delivery into the CNS. To this end, we investigated the effects of 15 nanoformulations of atazanavir (ATV), ritonavir (RTV), indinavir (IDV), and efavirenz (EFV) manufactured using different surfactants, including nanoART containing folate-coated surfactant (Table 1), on primary human brain microvascular endothelial cells (HBMEC), and the effects of MP-endothelial cell interactions on nanoART uptake, distribution, and entry into the CNS. We demonstrate uptake of nanoART by HBMEC, and this was associated with limited endothelial cytotoxicity. We further demonstrate transfer of nanoART from MP to HBMEC during MP-endothelial contact, with higher transfer for folate-coated nanoART. Administration of folate-coated nanoART to an animal model of HIV/AIDS showed efficient antiretroviral activity, drug-brain penetration, and decreased CNS inflammation in HIV-1-infected and nanoART-treated animals. We postulate that folate modification and endothelial uptake of nanoART could facilitate drug entry into the brain.

\section{Materials and methods Preparation and characterization of nanoART}

Freebase forms of RTV and EFV were obtained from Shengda Pharmaceutical Co (Zhejiang, People's Republic of China) and Hetero Labs, Ltd (Hyderabad, India). The sulfate forms of IDV and ATV were purchased from Longshem Co (Shanghai, People's Republic of China) and Gyma Laboratories of America Inc (Westbury, NY). The free bases of IDV and ATV were made using a $1 \mathrm{~N} \mathrm{NaOH}$ solution. Using the surfactants listed in Table 1, nanoART were manufactured from these protease inhibitors (IDV, RTV, ATV) and non-nucleoside reverse transcriptase inhibitor (EFV) as we previously

Table I Physical characteristics of drug nanoparticles

\begin{tabular}{|c|c|c|c|c|c|}
\hline Drug & Formulation & Method & Surfactant & Size $(\mathrm{nm})$ & Zeta potential $(\mathrm{mV})$ \\
\hline \multirow[t]{4}{*}{ IDV } & HI008 & Homogenized & PI88, Tween 80 & 1600 & -29.5 \\
\hline & $\mathrm{HIOI} 3 \mathrm{a}$ & Homogenized & $\mathrm{PI} 88, \mathrm{mPEG}_{2000}-\mathrm{DSPE}$ & 861 & -21.8 \\
\hline & $\mathrm{HIOI} 3 \mathrm{~b}$ & Homogenized & $\mathrm{PI} 88, \mathrm{mPEG}_{2000}-\mathrm{DSPE}$ & 819 & -23.6 \\
\hline & MI004 & Milled & $\mathrm{PI} 88, \mathrm{SDS}$ & 252 & -40.58 \\
\hline \multirow[t]{7}{*}{ RTV } & $\mathrm{H} 2014$ & Homogenized & $\mathrm{mPEG}_{2000}-\mathrm{DSPE}$ & 500 & -26.2 \\
\hline & $\mathrm{H} 2009$ & Homogenized & $\mathrm{mPEG}_{2000}-\mathrm{DSPE}$ & 204 & -21.1 \\
\hline & $\mathrm{H} 2013$ & Homogenized & $\mathrm{PI} 88, \mathrm{mPEG}_{2000}-\mathrm{DSPE}$ & 613 & -26.7 \\
\hline & $\mathrm{H} 2019$ & Homogenized & P407 & 471 & -21.5 \\
\hline & $\mathrm{H} 2020$ & Homogenized & $40 \%$ folate-P407/60\% P407 & 454 & -18.3 \\
\hline & M200I & Milled & $\mathrm{PI} 88$ & 347 & -13.5 \\
\hline & M2006 & Milled & $\mathrm{PI} 88, \mathrm{mPEG}_{2000}-\mathrm{DSPE}$ & 443 & -25.93 \\
\hline \multirow[t]{3}{*}{ ATV } & M300I & Milled & $\mathrm{PI} 88$ & 281 & -15.3 \\
\hline & $\mathrm{H} 3019$ & Homogenized & P407 & 383 & -10.2 \\
\hline & $\mathrm{H} 3020$ & Homogenized & $40 \%$ folate-P407/60\% P407 & 365 & -24.6 \\
\hline EFV & P4004 & Sonication & PLGA, PVA, CTAB & 300 & +7.4 \\
\hline \multirow[t]{4}{*}{ Fluconazole } & $\mathrm{H} 50 \mathrm{I} 3$ & Homogenized & $\mathrm{PI} 88, \mathrm{mPEG}_{2000}-\mathrm{DSPE}$ & 1143 & -25.3 \\
\hline & $\mathrm{H} 5014$ & Homogenized & $\mathrm{mPEG}_{2000}-\mathrm{DSPE}$ & 914 & -27.4 \\
\hline & M5004 & Milled & PI88, SDS & 530 & -20.47 \\
\hline & M5006 & Milled & PI88, mPEG ${ }_{2000}$-DSPE & 894 & -26.52 \\
\hline
\end{tabular}

Abbreviations: ATV, atazanavir; CTAB, cetyltrimethyl ammonium bromide; EFV, efavirenz; IDV, indinavir; mPEG 200 -DSPE, N-(carbonyl-methoxypolyethyleneglycol 2000)I,2 sn-glycero-3-phosphoethanolamine; PLGA, poly(lactic-coglycolic acid); PVA, polyvinyl alcohol; RTV, ritonavir; SDS, sodium dodecyl sulfate. 
described ${ }^{14,17,22}$ and as detailed in the data supplement. Drug concentration in the final nanoART suspension was determined using high-performance liquid chromatography (HPLC) as previously described. ${ }^{17}$ NanoART formulations were imaged by scanning electron microscopy as previously described. ${ }^{14,17,22}$

\section{Synthesis of folate poloxamer 407 (folate-P407)}

Folate-P407 was synthesized for the preparation of targeted folate nanoART. Briefly, poloxamer 407 (P407, SigmaAldrich, Saint Louis, MO) was activated with an eight-fold molar ratio of $p$-toluenesulfonyl chloride in dichloromethane (Sigma-Aldrich) with quantitative yield. The purified tosylated product was converted to azido-P407 by incubation with a sixfold molar ratio of sodium azide in N,N-dimethylformamide (Sigma-Aldrich) at $100^{\circ} \mathrm{C}$ overnight. Azido-P407 was then reduced to amine-P407 using a four-fold molar ratio of triphenylphosphine in tetrahydrofuran. To conjugate folate onto P407, folic acid (Sigma-Aldrich) was first activated with $N, N^{\prime}$-dicyclohexylcarbodiimide and $\mathrm{N}$-hydroxysuccinimide in dimethyl sulfoxide (all from Sigma-Aldrich), then a fourfold molar ratio of the resulting folate-N-hydroxysuccinimide ester was reacted with amine-P407 in dimethyl sulfoxide. The crude product was purified by precipitation in methanol and further purified with a Sephadex LH-20 column (GE Healthcare, Piscataway, NJ). A mixture consisting of $40 \%$ folate-P407 and $60 \%$ P407 was used to manufacture targeted folate nanoART through high-pressured homogenization.

\section{Labeling of nanoART}

NanoART were fluorescently labeled using lissamine rhodamine B 1,2-dihexadecanoyl-sn-glycero-3-phosphoethanolamine, triethylammonium salt (excitation $560 \mathrm{~nm}$, emission $580 \mathrm{~nm}$ ), or the Vybrant 3,3'-dioctadecyloxacarbo-cyanine perchlorate (DiD) cell-labeling solution (excitation $644 \mathrm{~nm}$ : emission $665 \mathrm{~nm}$ ) (Invitrogen, Carlsbad, CA). For labeling, $1 \mathrm{~mL}$ nanoART suspension was mixed overnight with $5 \mu \mathrm{L}$ of dye and nanoART pelleted by centrifugation at $20,000 \times \mathrm{g}$ for 5 minutes. NanoART particles were then washed at least five times with phosphate buffered saline (PBS) to remove all excess dye, and final drug concentration of the formulations was determined by HPLC.

\section{Human monocyte isolation and cultivation}

Monocytes were obtained from HIV-1, HIV-2, and hepatitis B seronegative donor leukopaks, separated by countercurrent centrifugal elutriation, and characterized as previously described. ${ }^{23,24}$ To obtain monocyte-derived macrophages (MDM), freshly elutriated monocytes were cultured for 7 days in Dulbecco's Modified Eagle Medium containing $2 \mathrm{mM} \mathrm{L}$-glutamine (Invitrogen), 10\% heat-inactivated human serum, $100 \mu \mathrm{g} / \mathrm{mL}$ gentamicin, and $10 \mu \mathrm{g} / \mathrm{mL}$ ciprofloxacin (Sigma-Aldrich) in the presence of $1000 \mathrm{U} / \mathrm{mL}$ human recombinant macrophage colony-stimulating factor.

\section{Brain endothelial cell culture and cytotoxicity assays}

Primary HBMEC were isolated from brain tissue obtained during surgical removal of epileptogenic cerebral cortex in adult patients as described previously ${ }^{24,25}$ and provided by Dr Marlys Witte and Dr Michael Bernas (University of Arizona, Tuscon, AZ). These brain tissues were collected under institutional review board-approved protocol at the University of Arizona. Routine evaluation for von Willebrand factor, Ulex europeus lectin, and CD31 (all from Abcam, Cambridge, MA) demonstrated that cells were $>99 \%$ pure. Freshly isolated cells were cultured as we previously described, ${ }^{24,25}$ and cells at passage 2-4 were used in this study. To determine any potential toxic effects of nanoART on HBMEC, confluent cells were treated with nanoART at $0.1 \mathrm{mM}$ to $0.27 \mathrm{mM}$ for 2 hours at $37^{\circ} \mathrm{C}, 5 \% \mathrm{CO}_{2}$. Following loading of each nanoformulation, cells were washed with serum-free culture media to remove excess drugs and cytotoxicity assessed over 48 hours using alamarBlue ${ }^{\mathrm{TM}}$ assay (Invitrogen) according to the manufacturer's instructions.

\section{Endothelial-MP nanoART transfers}

Primary HBMEC were cultured to confluence on glass coverslips as previously described. ${ }^{26}$ For endothelial-MDM communication, human MDM were loaded with $0.1 \mathrm{mM}$ rhodamine- or DiD-labeled nanoformulations of IDV, RTV, ATV, or EFV for 12 hours. Following nanoART loading, MDM were washed three times with PBS to remove any free nanoART, and cultured for 24 hours in drug-free media. Following the 24-hour culture, MDM media were collected and HBMEC were treated with this MDM-conditioned media for 2 hours. For endothelial-monocyte communication, freshly elutriated human monocytes were loaded with $0.1 \mathrm{mM}$ rhodamine- or DiD-labeled nanoformulations of IDV, RTV, ATV, or EFV for 12 hours. Following nanoART loading, monocytes were washed three times with PBS to remove any free nanoART. Monocytes were then cocultured with endothelial cells for 2 hours and HBMEC monolayers washed three to five times with PBS to remove monocytes. 


\section{Immunofluorescence and confocal microscopy}

Following endothelial-MDM and endothelial-monocyte coculture experiments, endothelial cells were washed, fixed, permeabilized with $0.1 \%$ triton X-100, and blocked for nonspecific binding with 3\% bovine serum albumin in PBS. Cells were incubated with antibodies to the endothelial cell marker von Willebrand factor (Abcam), 1:50 dilution, for 1 hour at room temperature, followed by staining (1 hour in the dark at room temperature) with secondary antibodies coupled with Alexa-488 (Invitrogen) at 1:500 dilutions. For immunofluorescence microscopy, stained cell monolayers were mounted in Prolong Gold antifade reagent containing DAPI (for nuclear staining) (Molecular Probes, Grand Island, NY) and examined using a fluorescent microscope (E800 Nikon, Melville, NY) connected to a color MagnaFire digital camera (Optronics, Goleta, CA). In separate experiments, HBMEC cultures were fluorescently labeled using the Vybrant 1,1'-dioctadecyl-3,3,3',3'-tetramethylindodicarbocyanine perchlorate (DiO) cell-labeling solution (excitation $484 \mathrm{~nm}$ : emission $501 \mathrm{~nm}$ ) and cocultured for 2 hours with monocytes loaded with rhodamine- or DiD-labeled nanoART. HBMEC monolayers were then washed three to five times with PBS to remove monocytes, mounted in Prolong Gold, and analyzed by fluorescence or confocal microscopy. Microscopic images were processed with 20 iterations of two-dimensional deconvolution at low noise level using Autoquant X software package (Media Cybernetics, Bethesda, MD).

To determine the localization of nanoART in endothelial cells, the triple-labeled cell samples were examined under an Olympus FV500-IX 81 confocal laser scanning imaging system. Several Z-series $(0.5 \mu \mathrm{M}$ optical sections) of images covering the apical and basal surfaces of the cells were collected from different areas of the cell samples using a sequential collection mode with triple laser lines excitation (405 nm for nucleus stains; $488 \mathrm{~nm}$ for von Willebrand factor/endothelial cell marker, and $543 \mathrm{~nm}$ for nanoART). For endothelial cells labeled with $\mathrm{DiO}$ and cocultured with monocytes loaded with rhodamine- or DiD-labeled nanoART, the triple laser lines excitations were $405 \mathrm{~nm}$ for nucleus stains, $484 \mathrm{~nm}$ for DiO/endothelial cells, and $543 \mathrm{~nm}$ or $644 \mathrm{~nm}$ for nanoART. Using the Olympus Fluoview imaging acquisition/ analysis software, data processing/analysis and side view image projections were carried out from line scans at the $\mathrm{XZ}$ axis and $\mathrm{YZ}$ axis from the extended-focusing images (merged from z-optical images). For better demonstration of the cellular localization of the nanoART particles, the XZ or YZ lines were selected to a position over specific nanoART and nonspecific/background staining for comparison of their position in the same side view images.

\section{Fluorescence-activated cell sorting}

For fluorescence-activated cell sorting (FACS) quantification of nanoART uptake by MP, monocytes or MDM were exposed to rhodamine- or DiD-labeled nanoART for 12 hours and washed three to five times with PBS to remove free nanoART. MP were then fixed by incubation in $1 \%$ paraformaldehyde for 20 minutes, washed, resuspended in PBS, and analyzed by FACS using a FACScan flow cytometer (BD Bioscience, San Jose, CA). The mean fluorescence channel and mean number of rhodamine-positive cells were derived using CellQuest software (BD Bioscience). To determine the levels of nanoART in MP and HBMEC following MP-endothelial communication, monocytes loaded with rhodamine- or DiD-labeled nanoART were cocultured for 2-4 hours with HBMEC (unlabeled or DiD-labeled), then washed three to five times to separate monocytes from endothelial cells. HBMEC and monocytes recovered from cocultures were then fixed by incubation in $1 \%$ paraformaldehyde for 20 minutes, washed, resuspended in PBS, and analyzed by FACS. The mean fluorescence channels and mean number of rhodamine-positive cells (monocytes), DiDpositive cells (HBMEC), and HBMEC double positive for rhodamine and DiD were derived using CellQuest software (BD Bioscience). For all FACS analyses, each experimental condition was performed in triplicate.

\section{Animals}

Male NOD/scid- $\gamma_{c}{ }^{\text {null }}$ (NSG) mice were obtained from the University of Nebraska Medical Center breeding colony, established in 2005. This colony is housed in pathogen-free conditions in accordance with ethical guidelines for the care of laboratory animals at the National Institutes of Health, and all procedures were approved by the Institutional Animal Care and Use Committee.

\section{Human cell isolation, transplantation, and viral infection}

Human peripheral blood lymphocytes (PBL) were purified from leukopaks by countercurrent centrifugal elutriation $^{23}$ and used to reconstitute the NSG mice. PBL were injected intraperitoneally into 8 -week-old NSG mice at $30 \times 10^{6} \mathrm{PBL} / \mathrm{mouse}$. For viral infections, the macrophagetropic HIV-1 ${ }_{\mathrm{ADA}}$, was propagated in human MDM; viral cultures were screened and found to be negative for endotoxin $(<10 \mathrm{pg} / \mathrm{mL})$ by Limulus amebocyte lysate assays 
(Associates of Cape Cod, Woods Hole, MA) and Mycoplasma ribosomal RNA (Gen-ProbeII, Gene Probe, San Diego, CA). The viral titer was assayed on MDM and determined to be $10^{5}$ tissue culture infectious dose ${ }_{50}\left(\mathrm{TCID}_{50}\right) / \mathrm{mL}$.

\section{Biodistribution and antiretroviral activity of folate-coated nanoART}

To determine the antiretroviral activity of folate-coated nanoART, NSG mice were reconstituted with PBL and infected 7 days later with $\mathrm{HIV}-1_{\mathrm{ADA}}$ (intraperitoneally) at a dose of $10^{4} \mathrm{TCID}_{50} /$ mouse. Two subcutaneous doses of folate-coated nanoART were administered, at 12 hours (Day 0) and 7 days after infection. NanoART were administered as folateP407-coated ATV and RTV (H3020 and H2020, Table 1), at $250 \mathrm{mg} / \mathrm{kg}$ each drug. This corresponded to a dose of $20.3 \mathrm{mg} / \mathrm{kg}$ in humans based on an interspecies scaling factor of 12.3. ${ }^{27}$ Blood and tissues were collected on Day 14 after the initial (Day 0) drug administration for quantitation of drug levels, tissue viral load, and human cell reconstitution. Drug concentrations were determined by ultraperformance liquid chromatography tandem mass spectrometry as described previously. $^{28}$

\section{Quantitative real-time polymerase chain reaction}

Total RNA was extracted from spleen sections and a halfhemisphere of each brain using TRIzol (Invitrogen). RNA was reverse transcribed to cDNA using the Verso cDNA kit (Fisher, Pittsburgh, PA). Quantitative real-time polymerase chain reaction (qRT-PCR) was performed to determine the expression of HIV-1 gag, human CD45, and mouse CD11b and the endogenous control glyceraldehyde-3-phosphate dehydrogenase (GAPDH). Taqman gene expression assays from Applied Biosystems (Carlsbad, CA) were used and the primer IDs were as follows: CD45: Hs00365634_g1, CD11b: Mm00434455_m1; and GAPDH: Hs99999905_m1. The primers and probe used for HIV-1 gag determination were as follows: forward, 5'-ACATCA AGC CAT GCA AAT -3'; reverse, 5'- ATC TGG CCT GGT GCAATAGG-3'; and probe (FAM), 5'-CATCAATGAGGAAGCTG CAGAATG GGA TAG A -3' (TAMRA). Gene expression was calculated using the delta-delta CT method (Applied Biosystems).

\section{Statistical analysis}

The Student's $t$-test was used for two-group analysis; multiple group comparisons were made by one- or two-way analysis of variance, and the general linear model procedures used GraphPad Prism 5.0d. Descriptive statistics for drug levels in vivo were summarized using median values due to the small sample size and non-normality of the data. Outcomes were compared between two groups using a Mann-Whitney test. The Tukey's post-test procedure was employed for multiple comparisons. The threshold for significance was $P<0.05$.

\section{Results \\ Manufacture and characterization of nanoART}

The characteristics of the nanoART used in this study were previously described. ${ }^{14,17,22}$ Briefly, nanoART, prepared from freebase drugs, were manufactured as nanosized drug crystals coated with phospholipid surfactants (IDV, ATV, and RTV) or as drug dissolved in a poly(lactic-coglycolic acid) copolymer solution (EFV). ${ }^{14,17,22}$ The nanoART morphology and shape have been described in our previous publications..$^{14,17,22}$ The physical properties of the nanosuspensions were similar in charge but varied in size (Table 1). The largest particle size was $1600 \mathrm{~nm}$ (H1008) while the smallest was $204 \mathrm{~nm}$ (H2009). The charges of all particles were $\leq-10 \mathrm{mV}$ with the exclusion of $\mathrm{P} 4004$, which was $+7.4 \mathrm{mV}^{14}$

\section{Cytotoxicity of nanoART in HBMEC}

NanoART showed limited cytotoxicity in human monocytes and macrophages. ${ }^{14}$ Herein, we evaluate the toxicity of 15 independent ART nanoformulations manufactured by homogenization, wet milling, and sonication, in HBMEC. These included ten homogenized (three IDV, five RTV, and two ATV), four milled (IDV, RTV, and ATV), and one sonicated (EFV) nanoART (Table 1). Similar concentrations of free ART drugs and similar amounts of each surfactant without drug were used as controls. Viability and functional tests were performed on HBMEC for each nanoART at $0.1 \mathrm{mM}$ based on prior studies, ${ }^{14-17}$ with the exception of $\mathrm{H} 2009$, which was investigated at $0.18 \mathrm{mM}$ and $0.27 \mathrm{mM}$, based on prior toxicity profiles. ${ }^{14}$ Evaluation of toxicity over 24 hours or 48 hours by alamarBlue ${ }^{\mathrm{TM}}$ redox assay showed that at $0.1 \mathrm{mM}$ concentration, nanoformulations of IDV (Figure 1A) and RTV with P188 and mPEG-DSPE as surfactants (Figure 1B), and EFV (Figure 1C) induced little or no HBMEC toxicities. The viability of endothelial cells exposed to these nanoformulations was similar to that of cells exposed to free ART. These values were not significantly different from those of cells not exposed to drug (Figure 1A-C). Higher concentrations of $\mathrm{H} 2009(0.27 \mathrm{mM})$ significantly increased toxicity in HBMEC (Figure 1D). Nanoformulations of RTV and ATV with P407 as surfactant (H2019 and H3019) or coated with folate-P407 (H2020 and H3020) induced more toxicity 

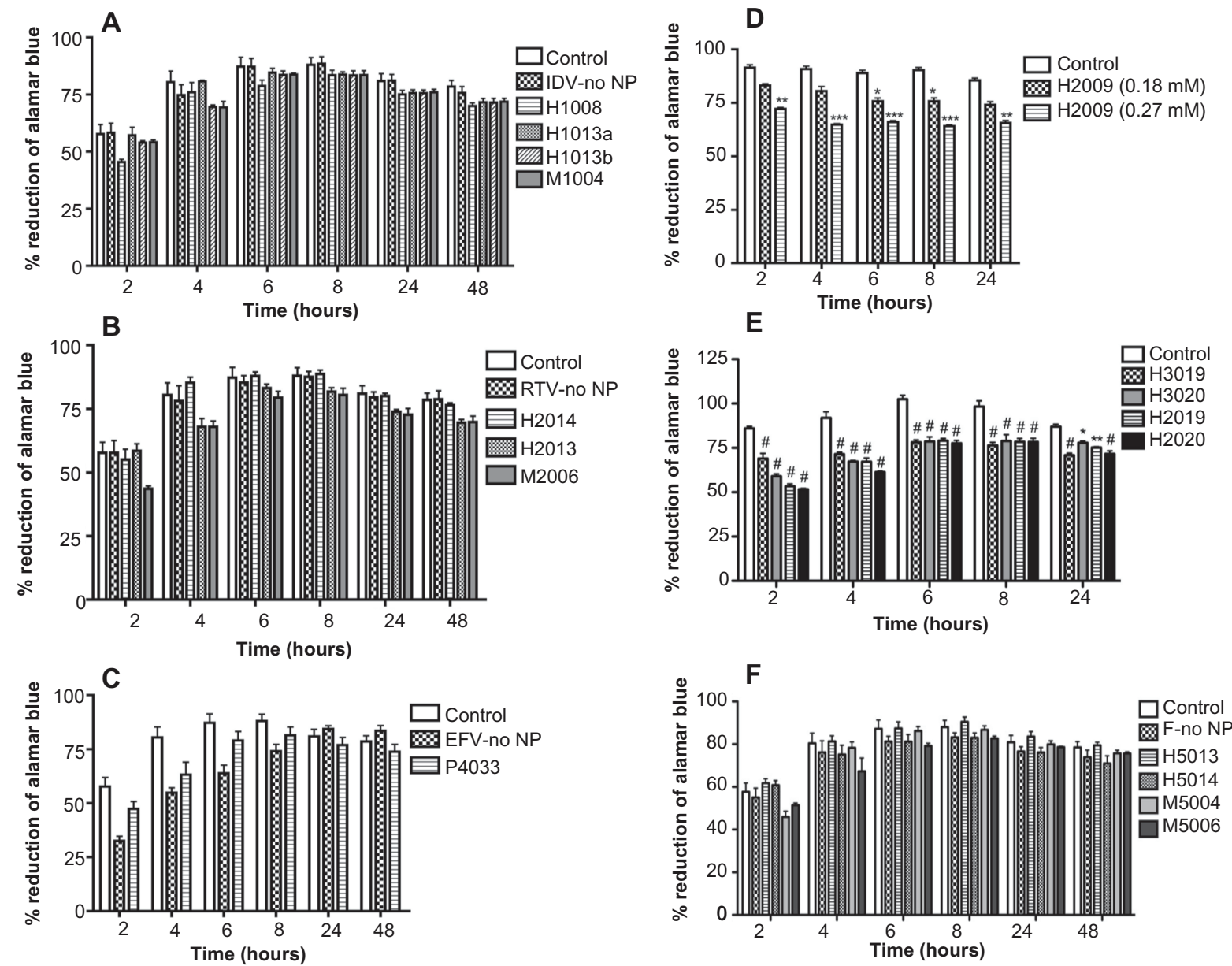

Figure I Effect of nanoformulated crystalline antiretroviral drugs on human brain microvascular endothelial cell (HBMEC) viability. Endothelial cells were loaded for 2 hours with four nanoformulations of indinavir (IDV) (A), six nanoformulations of ritonavir (RTV) (B and E), two nanoformulations of atazanavir (ATV) (D), or efavirenz (EFV) (C) at $0.1 \mathrm{mM}$. H2009 was used at $0.18 \mathrm{mM}$ and $0.27 \mathrm{mM}$. Controls consisted of untreated cells and cells exposed to similar concentrations of free (without nanoparticles [NP]) IDV, RTV, or EFV (IDV-no NP, RTV-no NP, EFV-no NP). Additional controls consisted of cells treated with similar concentrations of surfactant or combination of surfactants, and cells exposed to fluconazole alone (without surfactants, F-no NP) (F). Following drug loading, toxicity was assessed over 24 hours or 48 hours by alamarBlue ${ }^{\mathrm{TM}}$ assay. The ATV $(\mathrm{H} 3019, \mathrm{H} 3020)$ and RTV $(\mathrm{H} 2019, \mathrm{H} 2020)$ nanoformulations decreased HBMEC viability, but all other nanoformulated crystalline antiretroviral drugs at concentrations of $0.1 \mathrm{mM}$ had minimal or no effect on HBMEC viability. Similar concentrations of free IDV, RTV, or EFV did not alter HBMEC viability. At 0.27 mM drug concentration, increased toxicity was observed in cells exposed to $\mathrm{H} 2009$. All surfactants and fluconazole controls had no major effect on $\mathrm{HBMEC}$ viability.

Notes: For each experimental condition, $\mathrm{n}=3$. Figure shown is representative of three independent experiments. ${ }^{*} P<0.05$; ${ }^{* *} P<0.0 \mathrm{I} ;{ }^{* * *} \mathrm{P}<0.00 \mathrm{I}$; ${ }^{*} \mathrm{P}<0.000 \mathrm{I}$.

in HBMEC compared with untreated cells (Figure 1E, $\left.{ }^{\#} P<0.0001 ;{ }^{*} P<0.01,{ }^{*} P<0.05\right)$. Fluconazole was used to make surfactant-coated control nanoparticles, with homogenized (H5013 and H5014) and milled (M5004 and M5006) formulations. At $0.1 \mathrm{mM}$ concentration, these surfactant controls did not induce cytotoxicity (Figure 1F).

\section{MP-endothelial cell nanoART transfers}

Our previous works showed that nanoART could be loaded into human MDM and gradually released over time. ${ }^{14,17,22}$ To determine whether nanoART released by MP can be transferred to cells of the brain endothelium, we exposed HBMEC to conditioned media from MDM loaded with nanoART. Immunofluorescence analyses showed that following 2 hours of exposure of HBMEC to MDM-conditioned media, uptake of nanoART by endothelial cells was seen for all formulations tested (Figure 2B and C). The endothelial nature of our primary HBMEC was confirmed by staining with the endothelium-specific marker von Willebrand factor (Figure 2A), data showed DiO-labeled HBMEC (Figure 2D) and accumulation of nanoformulated drugs around the endothelial cell body and nucleus (Figure $2 \mathrm{C}$ and $\mathrm{F}$ and Figure 3 ). To determine whether nanoART can be transferred from MP to the brain endothelium during direct cell-to-cell contact, we cocultured HBMEC with human monocytes containing nanoART. Following 2 hours of coculture, transfer of nanoART from monocytes to HBMEC was observed for all ART nanoformulations and nanoART accumulated around the endothelial cell body and nucleus (Figure 2E and F and Figure 3). 

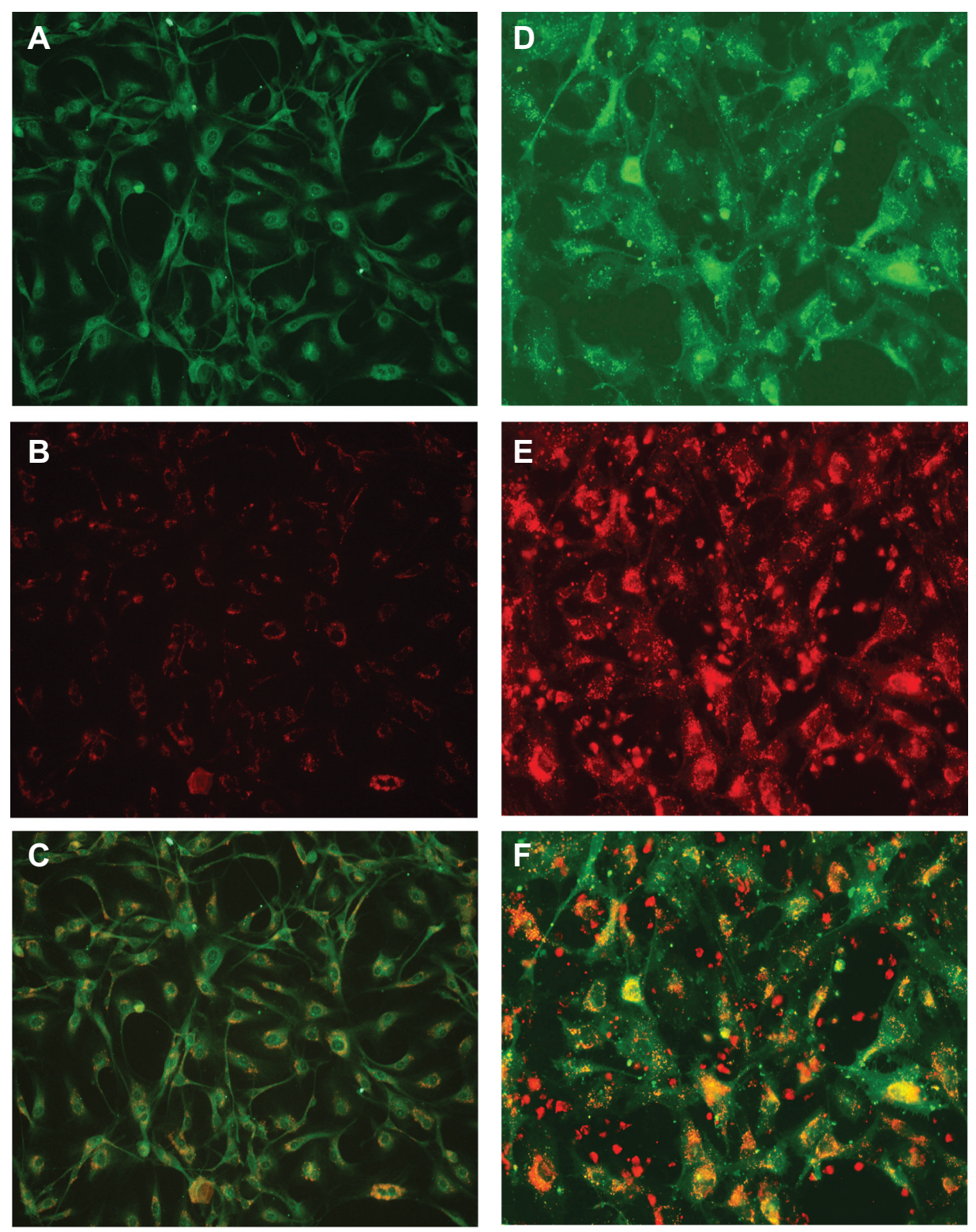

Figure 2 Uptake of nanoformulated crystalline antiretroviral drugs (nanoART) by human brain microvascular endothelial cells (HBMEC) following endothelial-mononuclear phagocyte cocultivation. (A-C) Primary HBMEC were exposed for 2 hours to conditioned media from monocyte-derived macrophages (MDM) loaded with rhodaminelabeled efavirenz (P4004) as described in the Methods section; HBMEC were then washed three times with phosphate buffered saline to remove MDM-conditioned media, and analyzed by fluorescence microscopy. Panels (B and $\mathbf{C}$ ) show endothelial cells uptake of nanoART (orange-yellow color) released by MDM. Staining with the endothelium-specific marker, von Willebrand factor (green, A) confirmed the endothelial nature of our primary HBMEC. (D-F) Primary HBMEC labeled with DiO (green, D) were cocultured for 2 hours with monocytes loaded with rhodamine-labeled ritonavir $(\mathrm{H} 20 \mathrm{l} 3)$, washed to remove monocytes, and analyzed by fluorescence microscopy. Panels ( $E$ and $\mathbf{F}$ ) show endothelial cells uptake of nanoART (orange-yellow color) during endothelial-monocyte cocultivation.

Note: All panels are at $200 \times$ magnification.

To further verify whether nanoART transferred to HBMEC enter endothelial cells, confocal microscopy was performed. This was done with the understanding that such events could increase the likelihood of nanoART passing though the BBB. When HBMEC are exposed to monocytes containing nanoART (H2013 [Figure 3A, B, and D] and H3020 [Figure 3E]) or exposed to MDMconditioned medium (H2013 [Figure 3C]), nanoART entered endothelial cells. Analyses using the $\mathrm{XZ}$ or
YZ line scan mode of the Olympus confocal imaging program demonstrated localization of nanoART in the cells cytoplasm, membrane-bound vesicles, and nucleus, with nanoART colocalized with endothelial cells vesicles (Figure 3, orange arrows). Confocal imaging also showed green membrane-bound vesicles in HBMEC (Figure 3, green, white arrows) and some nanoART inside HBMEC not colocalized with membrane-bound vesicles (Figure 3, red, white arrows). 

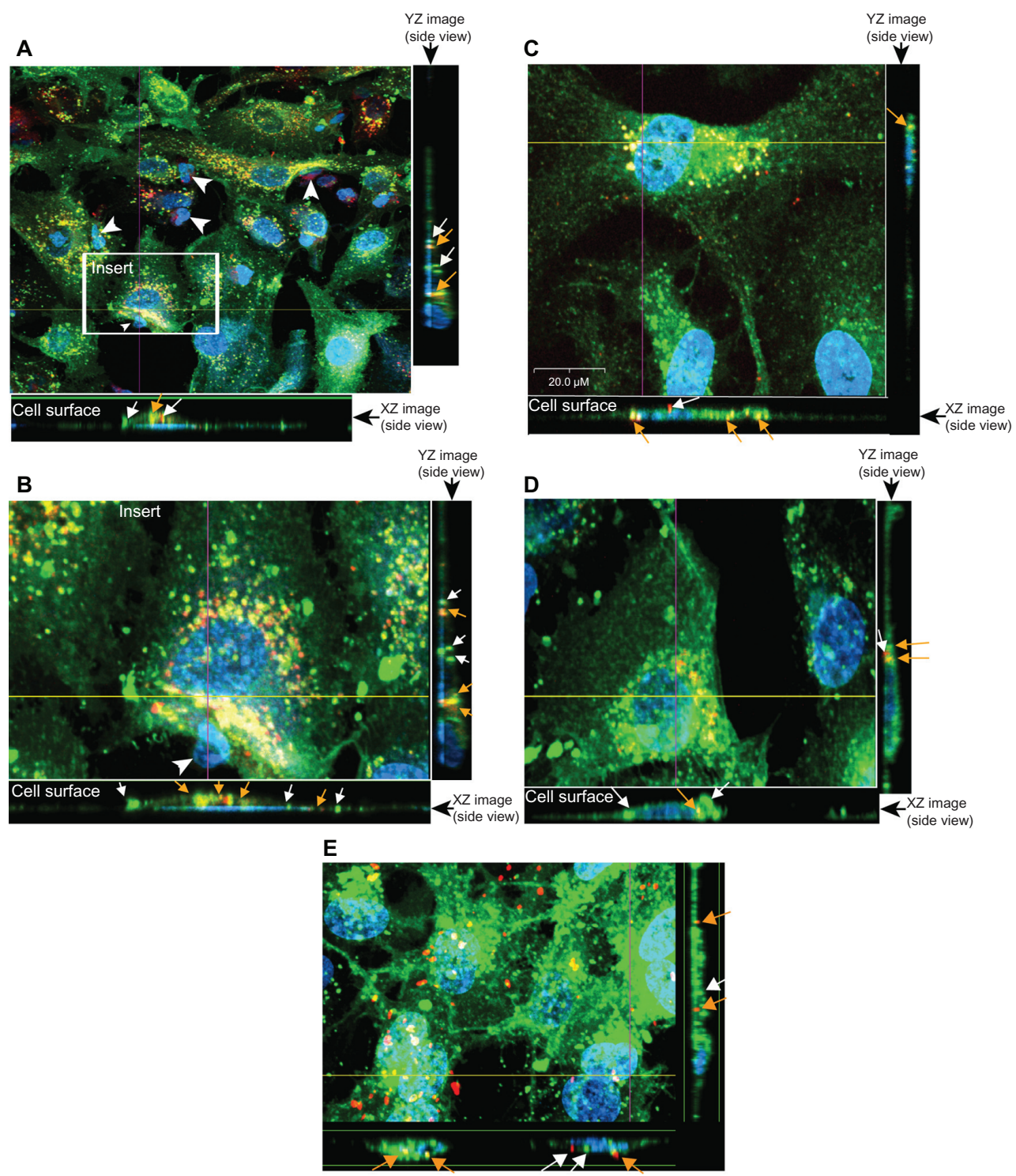

Figure 3 Endothelial cell nanoformulated crystalline antiretroviral drug (nanoART) uptake follows mononuclear phagocyte cocultivation. (A and B) Uptake of rhodaminelabeled ritonavir, $\mathrm{H} 20 \mathrm{I} 3$ (orange-yellow color) by primary human brain microvascular endothelial cells (HBMEC) (stained with DiO [green] and DAPI [blue for nucleus]) during endothelial-monocyte communication is visualized by confocal microscopy. Smaller nucleus (white arrow heads) shows monocytes (not removed during washes) in close cell-cell communication with HBMEC. (C and D) HBMEC (stained with DiO [green] and DAPI [blue for nucleus]) uptake of DiD-labeled ritonavir, H20I3 (orangeyellow color) from monocyte-derived macrophage-conditioned media (C), and during direct endothelial-monocyte communication (D). (E) HBMEC uptake of DiD-labeled folated-modified atazanavir (H3020) (orange-red color) during direct endothelial-monocyte communication.

Notes: Each set of images consists of a top view of cells and nanoART particles, a side view of the $X Z$ optical line scan through the yellow line, and a side view of the $Y Z$ optical line scan through the purple line. From those side view optical images, nanoART particles are seen inside the cells (arrows). For all panels, orange-colored arrows indicate nanoART (red fluorescence) colocalized with HBMEC vesicles; white arrows indicate nanoART (red fluorescence) or DiO-labeled membrane-bound vesicles (green fluorescence) that are not colocalized. Magnifications are at $630 \times(\mathbf{A}), 720 \times(\mathbf{E})$, and $1000 \times(\mathbf{B}-\mathbf{D})$.

\section{FACS quantification of nanoART in MP}

To further analyze nanoART uptake and transfer through MP-endothelial cell communication, we quantified the levels of nanoART in MP before and after coculture. Data showed strong uptake of nanoART by MP, with $56 \%$ and $94.9 \%$ of MDM positive for rhodamine when cells were exposed to $0.1 \mathrm{mM}$ and $0.5 \mathrm{mM}$ IDV nanoformulations, respectively (Figure 4A and B). Similarly, $97.6 \%$ and $98.6 \%$ of monocytes stained positive for rhodamine when cells were exposed to
$0.1 \mathrm{mM}$ and $0.5 \mathrm{mM}$ RTV nanoformulations, respectively (Figure 4C and D). Transfer of nanoART from MDM to brain endothelial cells following coculture was associated with a decrease of nanoART levels in monocytes (Figure 4A-E). In fact, when monocytes were loaded with $0.1 \mathrm{mM}$ IDV or RTV nanoformulations, 2 hours of coculture with HBMEC decreased nanoART levels in monocytes by $83 \%$ (IDV) and $71 \%$ (RTV) (Figure 4E, $P<0.001$ ). For monocytes loaded with $0.5 \mathrm{mM}$ IDV or RTV nanoformulations, 2 hours 

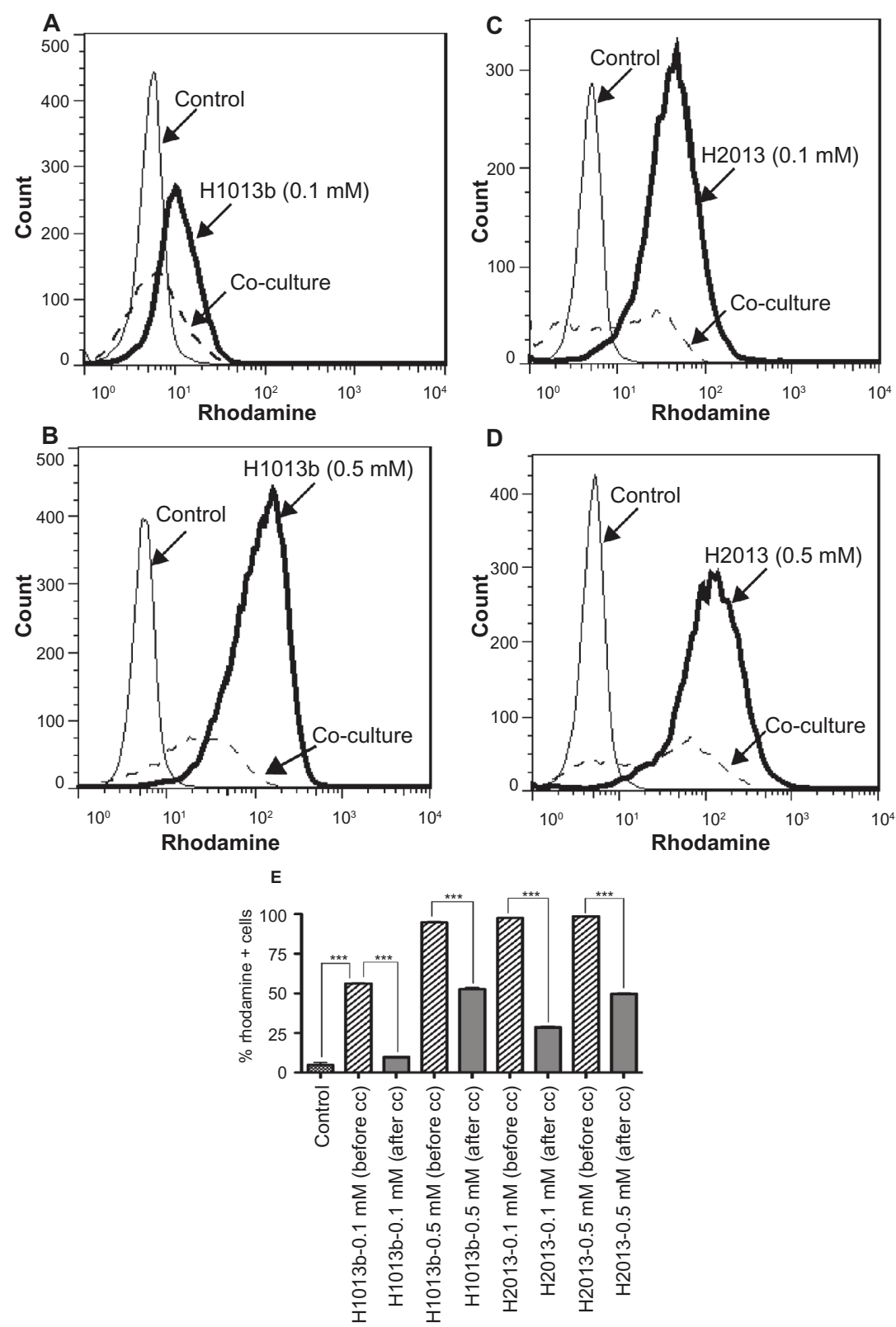

Figure 4 Transfer of nanoformulated crystalline antiretroviral drugs (nanoART) from mononuclear phagocyte to human brain microvascular endothelial cells (HBMEC) follows cell cocultivation. Monocytes loaded with $0.1 \mathrm{mM}$ or $0.5 \mathrm{mM}$ rhodamine-labeled indinavir (IDV) (HIOI3b, A and B) or ritonavir (RTV) (H20I3, C and D) nanoformulations were cocultured for 2 hours with HBMEC as described in the Methods section, and the levels of nanoART in monocytes before and after coculture quantified by fluorescence-activated cell sorting analysis. Coculture of monocytes loaded with 0.1 mM IDV (A) or RTV (C) nanoART with HBMEC decreased IDV and RTV nanoART levels in monocytes by $83 \%$ (A, dotted line, and E), and $71 \%$ (C, dotted line, and E). Coculture of monocytes loaded with $0.5 \mathrm{mM} \mathrm{IDV} \mathrm{(B)} \mathrm{or} \mathrm{RTV} \mathrm{(D)} \mathrm{nanoART}$ with HBMEC decreased IDV and RTV nanoART levels in monocytes by $44.5 \%$ (B, dotted line, and E), and $49.6 \%$ (D, dotted line, and E).

Notes: $* * * P<0.001$. Each experimental condition was performed in triplicate, and data shown are representative of four independent experiments.

of coculture with HBMEC decreased nanoART levels in monocytes by $44.5 \%$ (IDV) and $49.6 \%$ (RTV) (Figure 4E, $P<0.001)$.

\section{FACS quantification of nanoART in HBMEC following MP coculture}

FACS analysis of HBMEC (DiD-labeled) cocultured with monocytes loaded with rhodamine-labeled RTV nanoformulations showed that within the 2 hours of coculture,
nanoART were transferred to over $46 \%$ of HBMEC (Figure $5 \mathrm{~A}$ and $\mathrm{B})$. To determine the effect of folate modification on the transfer of nanoART from monocytes to HBMEC, we quantified the levels of folate-coated nanoART (H2020 and H3020) and their corresponding nonfolate formulations (H2019 and H3019) in HBMEC following coculture of endothelial cells with monocytes carrying nanoART. FACS analysis of HBMEC after 2 hours of coculture with monocytes loaded with DiD-labeled nanoART showed transfer of ATV (H3019) 


\section{A}
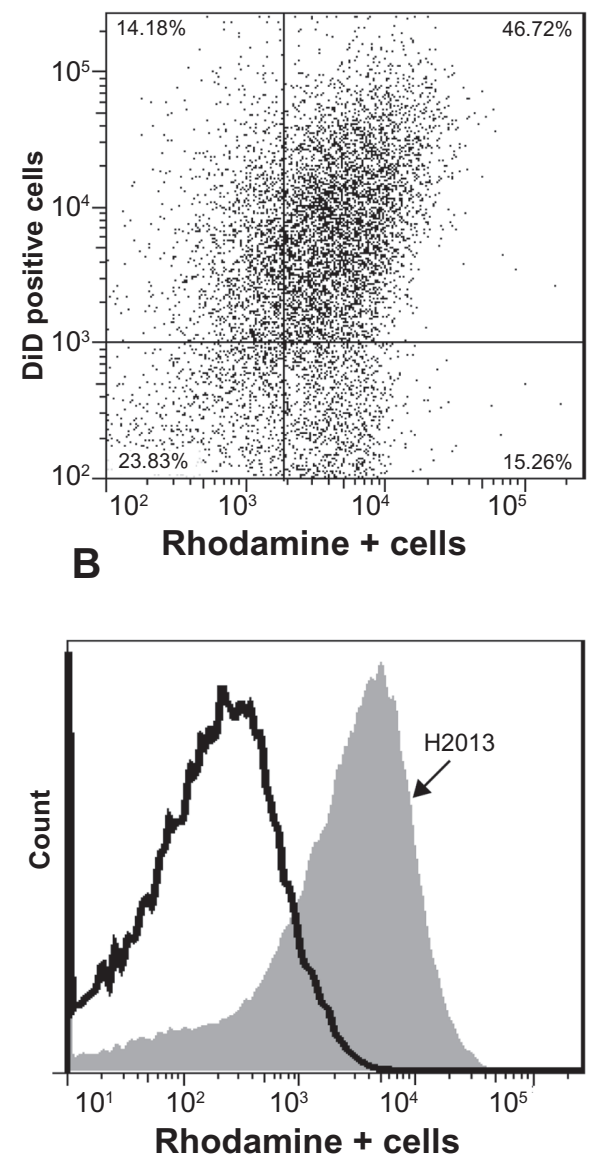

C

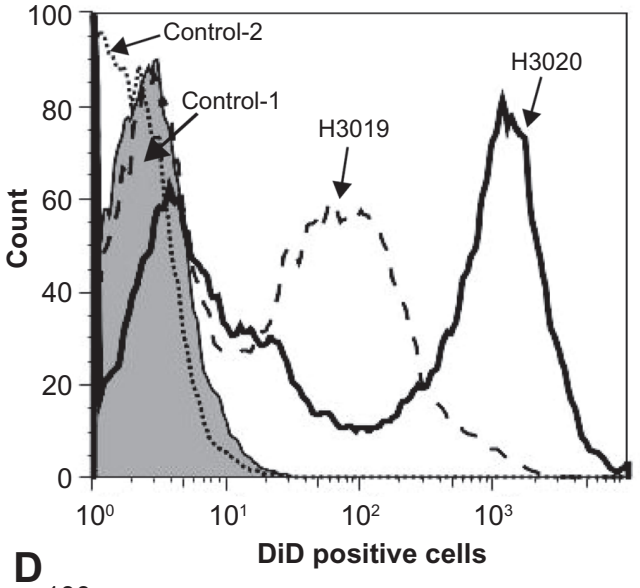

D

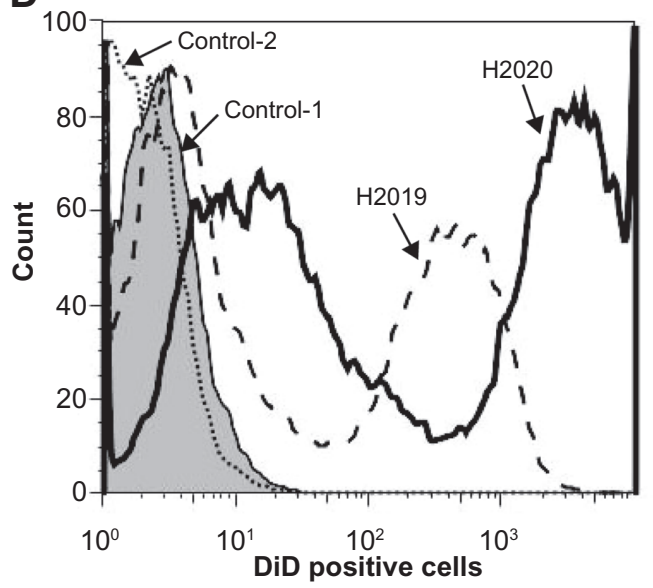

Figure 5 Quantification of nanoformulated crystalline antiretroviral drug (nanoART) transfer from mononuclear phagocytes to human brain microvascular endothelial cells (HBMEC). (A and B) HBMEC fluorescently labeled with DiD (excitation $644 \mathrm{~nm}$ ) were cocultured for 2 hours with monocytes loaded with rhodamine-labeled ritonavir (RTV) nanoformulations (excitation $543 \mathrm{~nm}$ ). Monocytes were removed by three to five washes and HBMEC harvested and analyzed by fluorescence-activated cell sorting. Endothelial-monocyte communication resulted in nanoART transfer to over $46 \%$ of HBMEC. (C and D) Unlabeled HBMEC were cocultured for 2 hours with monocytes loaded with DiD-labeled atazanavir (ATV) (C) and RTV (D) nanoformulations. Monocytes were removed by three to five washes and HBMEC harvested and analyzed by fluorescenceactivated cell sorting. Endothelial-monocyte communication resulted in transfer of ATV (H3019) and folate-coated ATV (H3020) nanoformulations to 52\% and 64.4\% of HBMEC, respectively $(\mathbf{C})$, and also resulted in transfer of RTV $(\mathrm{H} 2019)$ and folate-coated RTV $(\mathrm{H} 2020)$ nanoformulations to $50 \%$ and $77.3 \%$ of HBMEC, respectively (D).

Note: Each experimental condition was performed in triplicate, and data shown are representative of two independent experiments.

and folate-coated ATV (H3020) nanoformulations to $52 \%$ and $64 \%$ of HBMEC, respectively (Figure 5C). Similarly, coculture of HBMEC with monocytes loaded with DiDlabeled RTV formulations showed transfer of RTV (H2019) and folate-coated RTV (H2020) nanoformulations to 50\% and $77.3 \%$ of HBMEC, respectively (Figure 5D).

\section{Antiretroviral activity and brain penetration of folate-coated nanoART}

To determine the antiretroviral activity of nanoART, the expression of HIV-1 gag in infected folate-coated nanoARTtreated and -untreated (control) animals was quantitated in spleen and brain tissues by qRT-PCR. In folate-coated nanoART-treated mice, the level of HIV-1 gag gene expression was at the limit of sensitivity for the assay, while significantly higher levels of HIV-1 gag expression were observed in untreated mice (Figure 6A, $P<0.01$ ). To determine whether the differences in viral gene expression could be explained by differences in the numbers of human lymphocytes in the brain, expression of the human T-cell-specific marker CD45 gene expression was determined. CD45 expression levels were similar in brain tissues of untreated and treated mice (Figure 6B), indicating equal infiltration of human $\mathrm{T}$ lymphocytes into the CNS. Microglia activation and macrophage infiltration into the brain were determined by quantitating RNA expression of the cell adhesion molecule CD11b. CD11b gene expression was two-fold lower in brain tissues from folate-coated nanoART-treated mice compared with untreated mice $(P<0.01$, Figure 6C).

Tissue and sera drug levels in PBL-reconstituted HIV-1infected mice treated with two doses of $250 \mathrm{mg} / \mathrm{kg}$ folatecoated nanoART, H2020 and H3020 (Day 0 and Day 7), are 


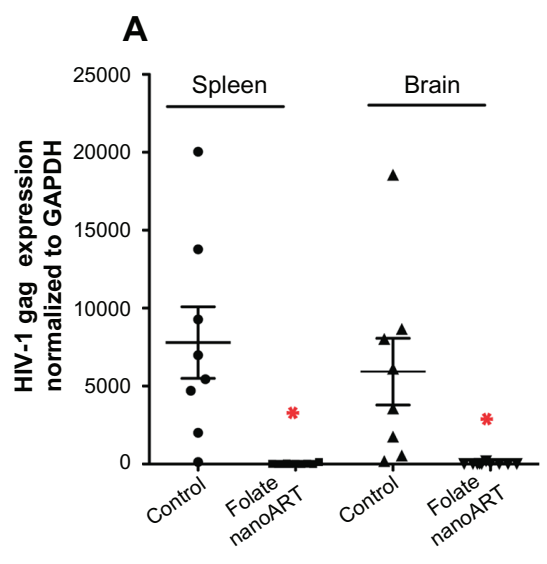

B
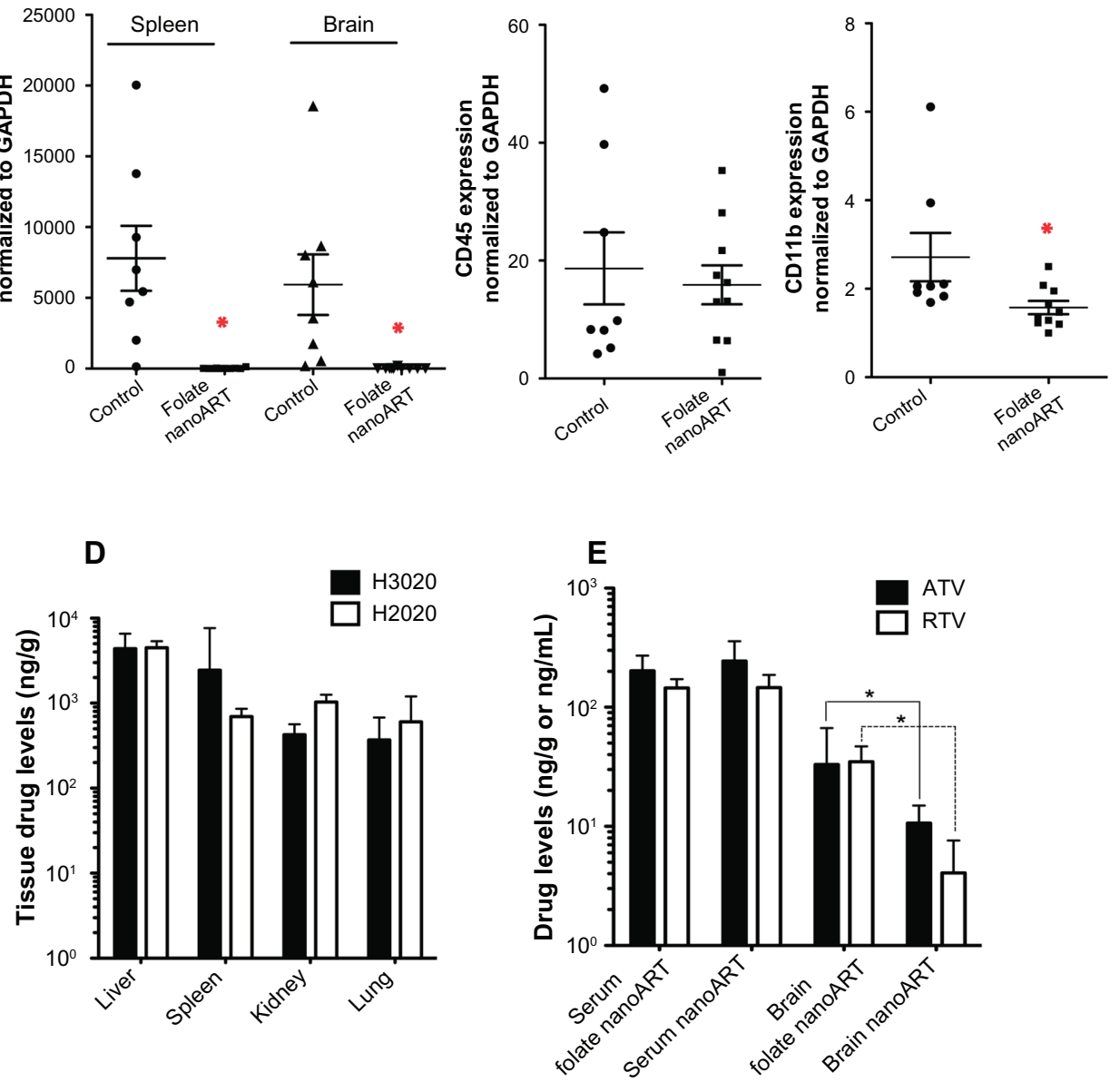

Figure 6 Antiretroviral activity and drug biodistribution of folate-coated nanoformulated crystalline antiretroviral drugs (nanoART). Folate-coated nanoART were injected subcutaneously on Days 0 and 7 as a combination of atazanavir (ATV) (H3020) and ritonavir (RTV) (H2020) (250 mg/kg each) to peripheral blood lymphocyte-NOD/scid- $\gamma_{c}^{\text {null }}$ mice infected with HIV-I ${ }_{A D A} 12$ hours before initial nanoART dose. Peripheral blood and tissues were collected on Day 14 after initial nanoART injection, followed by RNA extraction and real-time polymerase chain reaction for HIV-I gag (A), human CD45 (B), and mice CDI Ib (C), and normalized to glyceraldehyde-3-phosphate dehydrogenase mRNA. NanoART-treated mice showed a significant decrease in HIV-I gag in the spleen and brain $(\mathbf{A}, * P<0.0$ I), and CDI Ib RNA in brain $(\mathbf{C}$, $* P<0.04)$. CD45 levels were similar in the brains of treated and untreated mice (B). For (A-C), values are expressed as mean \pm standard error of the mean (bar \pm whisker). (D) Tissue (ng/g) and serum $(\mathrm{ng} / \mathrm{mL})$ drug levels in mice at 14 days after initial nanoART injection. (E) Serum $(\mathrm{ng} / \mathrm{mL})$ and brain (ng/g) drug levels in HIV-I-infected peripheral blood lymphocyte-NOD/ scid- $\gamma_{c}$ null mice treated with uncoated nanoART (H30l9 and H20l9) or folate-coated nanoART (H3020 and H2020) (250 mg/kg ATV/RTV, subcutaneously).

Notes: Significantly higher levels of ATV and RTV were detected in brain tissues of infected animals treated with folate-coated nanoART, compared with animals treated with uncoated nanoformulations ( $* P<0.02$ ). Drug levels are expressed as median \pm 25 th and 75 th percentiles due to non-normality of data. For panels $(\mathbf{A}-\mathbf{C})$, $n=8$ for control, and $\mathrm{n}=10$ for the drug-treated group. For panels $(\mathbf{D}$ and $\mathbf{E}), \mathrm{n}=\mathbf{8}$ in each group.

shown in Figures 6D and E. The highest ATV levels were observed in the liver and spleen (4372 ng/g and $2441 \mathrm{ng} / \mathrm{g}$ tissue, respectively). RTV levels were somewhat less than ATV levels in the spleen but similar to ATV levels in all other tissues. Next, we compared drug levels in the serum and brain of mice treated with folate-coated nanoART (H2020 and H3020) and the corresponding noncoated nanoART (H2019 and H3019) (Figure 6E). Interestingly, brain ATV and RTV levels in folate-coated nanoART-treated mice were three- to four-fold higher than in mice treated with noncoated nanoART. Brain ATV and RTV levels in animals treated with folate-coated nanoART were $33 \mathrm{ng} / \mathrm{g}$ and $34.5 \mathrm{ng} / \mathrm{g}$, respectively, while ATV and RTV levels in animals treated with nonmodified nanoART were $10.6 \mathrm{ng} / \mathrm{g}$ and $4.1 \mathrm{ng} / \mathrm{g}$, respectively (Figure 6E, $P<0.02$ ). In contrast, serum ATV concentrations were similar in mice treated with folatecoated nanoART (202.2 ng/mL) and nonmodified nanoART ( $244.1 \mathrm{ng} / \mathrm{mL})$. Serum RTV concentrations were also similar in mice treated with folate-coated nanoART $(145.4 \mathrm{ng} / \mathrm{mL})$ and noncoated nanoART (146.5 ng/mL).

\section{Discussion}

A major limitation of cART rests in their inability to penetrate the CNS. Thus, even when systemic viral load is controlled with ART, the brain remains an HIV sanctuary. ${ }^{6-9} \mathrm{We}$ hypothesize that nanomedicine-based ART could effect viral 
eliminations from sanctuaries such as the CNS. Our prior works demonstrated efficient cellular uptake, distribution, and release of nanoART by MP in both in vitro and animal models of human disease ${ }^{15-17,20-22}$ and showed limited toxicities in cells and tissue. ${ }^{14}$ Thus, we also hypothesize that circulating monocyte-macrophages carrying nanoART could transfer the drug to HBMEC, the major cells of the BBB, through cellcell communication and, as such, may enhance ART entry into the brain. In the current report, we investigated HBMEC uptake, in vivo drug distribution, antiretroviral activity, and CNS penetration of nanoART. To first ensure that nanoART would not cause adverse effects to brain endothelial cells, 13 protease inhibitor and non-nucleoside reverse transcriptase inhibitor formulations were prepared by homogenization, wet milling, or sonication and assessed for cytotoxicities. Nine nanoformulations showed little or no HBMEC cytotoxicity at $0.1 \mathrm{mM}$, a concentration that significantly suppresses viral replication for more than 2 weeks following a single nanoART exposure. ${ }^{17,22}$ The increased endothelial toxicity observed with four of the nanoformulations could be due to the surfactant, as these were the only formulations prepared using P407.

We also demonstrated efficient uptake of nanoART by brain endothelial cells. During such endothelial cell-monocytes/ MDM engagements, increased uptake of nanoART by HBMEC correlated with decreased levels of nanoART in donor monocytes and macrophages. These results suggested a novel means of ART CNS delivery. Efficient uptake and release of nanoART by MP was shown in our works. ${ }^{17,20,22}$ Our current data showing efficient uptake of nanoART by HBMEC exposed to MDM-conditioned media and during direct endothelial-MP contact support the idea that nanoART released by $\mathrm{MDM}$ can be taken up by cells of the $\mathrm{BBB}$, and that nanoART can be transferred from the periphery to the brain. Confocal microscopy analyses showed nanoART particles inside endothelial cells, including cell vesicles and nucleus. Interestingly, folate modification enhanced the transfer of nanoART from MP to HBMEC, and was associated with enhanced BBB penetration in vivo. Thus, nanoART formulated by modifying nanoparticle surfaces with targeted molecules could increase drug uptake into HBMEC and accelerate CNS drug entry. The mechanisms of this enhanced uptake and CNS entry of folate-coated nanoART remains to be determined, including whether the process involves carrier-mediated transport, receptor-mediated endocytosis, or adsorptive endocytosis of the drug-laden particles. It has been shown that folic acid can be transported across the cell membrane by using the reduced folate carrier, the folate receptor (FR), or the folic acid pump..$^{29,30}$ Although there are limited numbers of FR on the BBB, FR expression can facilitate drug entry into the CNS. ${ }^{30,31}$ It has also been reported that mice and human choroid plexus express substantial levels of FR, and these FR are potential therapeutic targets for choroid plexus tumors. ${ }^{32}$ Other tumors overexpress the FR, and folate modification has been shown to significantly improve cellular uptake and efficacy of anticancer drugs. ${ }^{33-36}$ Tagging folate to gene therapy vectors and immunotherapeutic agents has also been shown to improve drug delivery. ${ }^{34,37,38}$

It is well known that other receptors, such as the transferrin and mannose receptors, expressed on brain endothelial cells can also facilitate the transport of nanoparticles across the BBB. ${ }^{39} \mathrm{~A}$ five-fold increase in didanosine uptake was demonstrated when the drug was conjugated to mannancoated nanoparticles, with significantly increased didanosine concentration in the spleen, brain, and lymph nodes. ${ }^{40}$ The authors suggested that mannan-coated nanoparticles targeted didanosine to cells by mannosyl receptor-mediated endocytosis. ${ }^{40}$ In vitro studies also showed increased endothelial uptake of solid lipid ATV and transferrin-tagged saquinavir nanoparticles compared with nontagged drugs. ${ }^{41,42}$ The current study shows localization of nanoART in endothelial cell vesicles, suggesting that vesicular transport may be involved in nanoART uptake and trafficking in HBMEC. Future investigations will explore the types of vesicles involved and the molecular mechanisms through which endothelial cells uptake nanoART during endothelial-MP communication.

NanoART treatment of HIV-1-infected humanized mice was associated with significantly decreased viral loads. Mice were reconstituted with human peripheral blood lymphocytes; the leukocyte common antigen CD45 is abundantly expressed in human lymphocytes, and HIV infection is often associated with increased infiltration of leukocytes into the CNS, including T lymphocytes. ${ }^{43,44}$ Our study showed equal infiltration of human T lymphocytes into the CNS of untreated and nanoART-treated infected mice, indicating that the observed differences in viral gene expression are not due to differences in the numbers of human lymphocytes in the brain. NanoART treatment of infected mice was also associated with significantly decreased brain CD11b RNA levels. This suggested that in addition to reducing viremia, nanoART decrease microglial activation and/or macrophage transmigration into the brain. Our previous works in vitro also showed that nanoART at $0.1 \mathrm{mM}$ can suppress HIV replication in macrophages for up to 15 days. ${ }^{17,22}$ Overall, the current study showed that this nanoART concentration induced limited cytotoxicity in primary HBMEC. Significantly, we show transfer of nanoART from MP to cells of the brain endothelium through direct 
MP-endothelial cell communication, with increased drug transfer and brain penetration for folate-coated nanoART, correlating with decreased CNS viral load and decreased MP activation. Because most of the current ART drugs have a very poor BBB penetration, treatment of HIV CNS infection remains elusive and the brain remains a major viral reservoir. Thus, it is critical to devise strategies to improve the penetration of ART drugs into the CNS. Our current study suggests that nanoformulations of ART drugs could improve drug entry into the CNS and other viral sanctuaries, and thus help reduce viral-associated injury in these tissues and organs.

\section{Acknowledgments}

We thank Ms Robin Taylor for graphical support, Hong Li and Rafael Bressani for technical assistance, the University of Nebraska Medical Center Cell Analysis and FACS core facility for assistance with the FACS analysis, and the University of Nebraska-Lincoln microscopy core facility for assistance in confocal analyses. This work was supported by National Institutes of Health grants RO1MH081780 (to GDK); 1P01DA028555-01, P01 NS043985, P30 MH062261, and P20 RR15635 (to HEG and GDK); and 2R37 NS36126, P01 NS31492, P01 MH64570, and 2R01 NS034239 (to HEG).

\section{Disclosure}

The authors report no conflicts of interest in this work.

\section{References}

1. Yadav A, Collman RG. CNS inflammation and macrophage/microglial biology associated with HIV-1 infection. J Neuroimmune Pharmacol. 2009;4(4):430-447.

2. Ellis RJ, Badiee J, Vaida F, et al. CD4 nadir is a predictor of HIV neurocognitive impairment in the era of combination antiretroviral therapy. AIDS. 2011;25(14):1747-1751.

3. Grant I, Sacktor N, McArthur J. HIV neurocognitive disorders. In: Gendelman HE, Grant I, Everall IP, Lipton SA, Swindells S, editors. The Neurology of AIDS. 2 ed. New York: Oxford University Press; 2005:357-373.

4. Antinori A, Arendt G, Becker JT, et al. Updated research nosology for HIV-associated neurocognitive disorders. Neurology. 2007;69(18): 1789-1799.

5. Heaton RK, Clifford DB, Franklin DR Jr, et al. HIV-associated neurocognitive disorders persist in the era of potent antiretroviral therapy: CHARTER Study. Neurology. 2010;75(23):2087-2096.

6. Persidsky Y, Gendelman HE. Mononuclear phagocyte immunity and the neuropathogenesis of HIV-1 infection. J Leukoc Biol. 2003;74(5):691-701.

7. Nath A, Sacktor N. Influence of highly active antiretroviral therapy on persistence of HIV in the central nervous system. Curr Opin Neurol. 2006;19(4):358-361.

8. Alexaki A, Liu Y, Wigdahl B. Cellular reservoirs of HIV-1 and their role in viral persistence. Curr HIV Res. 2008;6(5):388-400.

9. McArthur JC, Steiner J, Sacktor N, Nath A. Human immunodeficiency virus-associated neurocognitive disorders: Mind the gap. Ann Neurol. 2010;67(6):699-714.
10. Marra CM, Zhao Y, Clifford DB, et al. Impact of combination antiretroviral therapy on cerebrospinal fluid HIV RNA and neurocognitive performance. AIDS. 2009;23(11):1359-1366.

11. Price RW, Spudich S. Antiretroviral therapy and central nervous system HIV type 1 infection. J Infect Dis. 2008;197 Suppl 3:S294-S306.

12. Sosnik A, Chiappetta DA, Carcaboso AM. Drug delivery systems in HIV pharmacotherapy: what has been done and the challenges standing ahead. J Control Release. 2009;138(1):2-15.

13. McMillan J, Batrakova E, Gendelman HE. Cell delivery of therapeutic nanoparticles. Prog Mol Biol Transl Sci. 2011;104:563-601.

14. Bressani RF, Nowacek AS, Singh S, et al. Pharmacotoxicology of monocyte-macrophage nanoformulated antiretroviral drug uptake and carriage. Nanotoxicology. 2011;5(4):592-605.

15. Dou H, Destache CJ, Morehead JR, et al. Development of a macrophagebased nanoparticle platform for antiretroviral drug delivery. Blood. 2006;108(8):2827-2835.

16. Dou H, Morehead J, Destache CJ, et al. Laboratory investigations for the morphologic, pharmacokinetic, and anti-retroviral properties of indinavir nanoparticles in human monocyte-derived macrophages. Virology. 2007;358(1):148-158.

17. Nowacek AS, Miller RL, McMillan J, et al. NanoART synthesis, characterization, uptake, release and toxicology for human monocyte-macrophage drug delivery. Nanomedicine (Lond). 2009;4(8): 903-917.

18. Nowacek A, Gendelman HE. NanoART, neuroAIDS and CNS drug delivery. Nanomedicine (Lond). 2009;4(5):557-574.

19. Gorantla S, Dou H, Boska M, et al. Quantitative magnetic resonance and SPECT imaging for macrophage tissue migration and nanoformulated drug delivery. J Leukoc Biol. 2006;80(5):1165-1174.

20. Dou H, Grotepas CB, McMillan JM, et al. Macrophage delivery of nanoformulated antiretroviral drug to the brain in a murine model of neuroAIDS. J Immunol. 2009;183(1):661-669.

21. Beduneau A, Ma Z, Grotepas CB, et al. Facilitated monocytemacrophage uptake and tissue distribution of superparmagnetic ironoxide nanoparticles. PLoS One. 2009;4(2):e4343.

22. Nowacek AS, Balkundi S, McMillan J, et al. Analyses of nanoformulated antiretroviral drug charge, size, shape and content for uptake, drug release and antiviral activities in human monocyte-derived macrophages. J Control Release. 2011;150(2):204-211.

23. Gendelman HE, Orenstein JM, Martin MA, et al. Efficient isolation and propagation of human immunodeficiency virus on recombinant colony-stimulating factor 1-treated monocytes. J Exp Med. 1988;167(4):1428-1441.

24. Kanmogne GD, Schall K, Leibhart J, Knipe B, Gendelman HE, Persidsky Y. HIV-1 gp120 compromises blood-brain barrier integrity and enhances monocyte migration across blood-brain barrier: implication for viral neuropathogenesis. J Cereb Blood Flow Metab. 2007;27(1): 123-134.

25. Chaudhuri A, Yang B, Gendelman HE, Persidsky Y, Kanmogne GD. STAT1 signaling modulates HIV-1-induced inflammatory responses and leukocyte transmigration across the blood-brain barrier. Blood. 2008;111(4):2062-2072.

26. Yang B, Akhter S, Chaudhuri A, Kanmogne GD. HIV-1 gp120 induces cytokine expression, leukocyte adhesion, and transmigration across the blood-brain barrier: modulatory effects of STAT 1 signaling. Microvasc Res. 2009;77(2):212-219.

27. Stoddart CA, Bales CA, Bare JC, et al. Validation of the SCID-hu Thy/ Liv mouse model with four classes of licensed antiretrovirals. PLoS One. 2007;2(7):e655.

28. Huang J, Gautam N, Bathena SP, et al. UPLC-MS/MS quantification of nanoformulated ritonavir, indinavir, atazanavir, and efavirenz in mouse serum and tissues. J Chromatogr B Analyt Technol Biomed Life Sci. 2011;879(23):2332-2338

29. Zhao R, Seither R, Brigle KE, Sharina IG, Wang PJ, Goldman ID. Impact of overexpression of the reduced folate carrier (RFC1), an anion exchanger, on concentrative transport in murine L1210 leukemia cells J Biol Chem. 1997;272(34):21207-21212. 
30. Beduneau A, Saulnier P, Benoit JP. Active targeting of brain tumors using nanocarriers. Biomaterials. 2007;28(33):4947-4967.

31. Wu D, Pardridge WM. Blood-brain barrier transport of reduced folic acid. Pharmaceutical Research. 1999;16(3):415-419.

32. Patrick TA, Kranz DM, van Dyke TA, Roy EJ. Folate receptors as potential therapeutic targets in choroid plexus tumors of SV40 transgenic mice. J Neurooncol. 1997;32(2):111-123.

33. Wang X, Li J, Wang Y, et al. HFT-T, a targeting nanoparticle, enhances specific delivery of paclitaxel to folate receptor-positive tumors. ACS Nano. 2009;3(10):3165-3174.

34. Kularatne SA, Low PS. Targeting of nanoparticles: folate receptor. Methods Mol Biol. 2010;624:249-265.

35. Nukolova NV, Oberoi HS, Cohen SM, Kabanov AV, Bronich TK. Folatedecorated nanogels for targeted therapy of ovarian cancer. Biomaterials. 2011;32(23):5417-5426.

36. Lu J, Li Z, Zink JI, Tamanoi F. In vivo tumor suppression efficacy of mesoporous silica nanoparticles-based drug-delivery system: enhanced efficacy by folate modification. Nanomedicine. 2012;8(2):212-220.

37. Reddy JA, Low PS. Enhanced folate receptor mediated gene therapy using a novel pH-sensitive lipid formulation. J Control Release. 2000;64(1-3):27-37.

38. Lu Y, Low PS. Folate targeting of haptens to cancer cell surfaces mediates immunotherapy of syngeneic murine tumors. Cancer Immunol Immunother. 2002;51(3):153-162.

39. Beduneau A, Hindre F, Clavreul A, Leroux JC, Saulnier P, Benoit JP. Brain targeting using novel lipid nanovectors. J Control Release. 2008;126(1):44-49.
40. Kaur A, Jain S, Tiwary AK. Mannan-coated gelatin nanoparticles for sustained and targeted delivery of didanosine: in vitro and in vivo evaluation. Acta Pharm. 2008;58(1):61-74.

41. Chattopadhyay N, Zastre J, Wong HL, Wu XY, Bendayan R. Solid lipid nanoparticles enhance the delivery of the HIV protease inhibitor, atazanavir, by a human brain endothelial cell line. Pharm Res. 2008; 25(10):2262-2271.

42. Mahajan SD, Roy I, Xu G, et al. Enhancing the delivery of anti retroviral drug "Saquinavir" across the blood brain barrier using nanoparticles. Curr HIV Res. 2010;8(5):396-404.

43. Cosenza-Nashat MA, Kim MO, Zhao ML, Suh HS, Lee SC. CD45 isoform expression in microglia and inflammatory cells in HIV-1 encephalitis. Brain Pathol. 2006;16(4):256-265.

44. Buckner CM, Luers AJ, Calderon TM, Eugenin EA, Berman JW. Neuroimmunity and the blood-brain barrier: molecular regulation of leukocyte transmigration and viral entry into the nervous system with a focus on neuroAIDS. J Neuroimmune Pharmacol. 2006;1(2):160-181.

45. Nowacek AS, Balkundi S, McMillan J, et al. Analyses of nanoformulated antiretroviral drug charge, size, shape and content for uptake, drug release and antiviral activities in human monocyte-derived macrophages. J Control Release. 2011;150(2):204-211.

46. Balkundi S, Nowacek AS, Veerhubotla RS, et al. Comparative manufacture and cell-based delivery of antiretroviral nanoformulations. Int J Nanomedicine. 2011;6:3393-3404. 


\section{Data supplement \\ Materials and methods}

Preparation and characterization of nanoART

The surfactants used for nanoART included poloxamer-188 and -407 (P188, P407 Sigma-Aldrich); N-(carbonylmethoxypolyethyleneglycol 2000)-1,2 sn-glycero-3phosphoethanolamine ( $\mathrm{mPEG}_{2000}$-DSPE; Genzyme, Cambridge, MA); sodium dodecyl sulfate (SDS; Bio-Rad Laboratories, Hercules, CA); poly(lactic-coglycolic acid) (PLGA; Sigma-Aldrich); and cetyltrimethyl ammonium bromide (CTAB; Sigma-Aldrich) (Table 1). Using these surfactants, nanoART were manufactured from three protease inhibitors (IDV, RTV, ATV), and one non-nucleoside reverse transcriptase inhibitor (EFV) as we previously described. ${ }^{14,17,22}$ Briefly, surfactants were resuspended in $10 \mathrm{mM}$ HEPES, $\mathrm{pH} 7.8$, and freebase drug was added ( $0.6 \%$ by weight). Combinations of drug and surfactant were as follows: ATV in $0.5 \% \mathrm{P} 188$ or P407; IDV in $0.5 \% \mathrm{P} 188$ and $0.5 \% \mathrm{SDS}, 0.1 \% \mathrm{mPEG}_{2000} \mathrm{DSPE}$; and RTV in $0.3 \% \mathrm{P} 188$ and $0.1 \% \mathrm{mPEG}_{2000}$ DSPE. A homogeneous dispersion was formed by agitation with an Ultraturrax T-18 rotor-stator mixer (IKA ${ }^{\circledR}$ Works Inc, Wilmington, NC). For preparation of suspensions by homogenization, mixtures were transferred to an Avestin C5 high-pressure homogenizer (Avestin, Inc, Ottawa, ON, Canada) and extruded at 20,000 pounds per square inch for about 30 passes or until the desired particle size was reached. ${ }^{14,17}$ Particle size, polydispersity, and surface charge (zeta potential) were determined by dynamic light scattering using a Malvern Zetasizer Nano Series Nano-ZS (Malvern Instruments Inc, Westborough, MA). After the desired particle size was achieved, samples were centrifuged at $10,000 \times \mathrm{g}$ for 30 minutes at $4^{\circ} \mathrm{C}$. The resulting pellet was resuspended in surfactant solution containing 9.25\% sucrose to adjust tonicity. For preparation of nanosuspensions by wet milling, mixtures were transferred to a NETZSCH MicroSeries Wet Mill (NETZSCH Premier Technologies, LLC, Exton, PA) with $50 \mathrm{~mL}$ of $0.8 \mathrm{~mm}$ grinding media (zirconium ceramic beads, Saint-Gobain ZirPro, La Pontet, France). The sample was milled for 30 minutes to 1 hour at speeds ranging from $600 \mathrm{rpm}$ to $4320 \mathrm{rpm}$ until the desired particle size was achieved. ${ }^{45,46}$ Nanoparticles of fluconazole (IVAX Pharmaceuticals, Miami, FL) were manufactured using the same methods mentioned previously. ${ }^{14}$ Drug concentrations in the final suspensions were determined using HPLC as previously described. ${ }^{17}$

EFV nanoparticles were made by sonication; $6 \mathrm{~g}$ of PLGA, RESOMER RG 752 H (Sigma-Aldrich) was added to $50 \mathrm{~mL}$ dichloromethane (HPLC grade) with $1 \%$ cetyltrimethyl ammonium bromide (CTAB; Sigma-Aldrich) and mixed until complete dissolution. Freebase EFV (1.25 g) was added to the dichloromethane/PLGA solution and mixed to obtain complete dissolution. This solution was added to a 1\% polyvinyl alcohol (PVA) (Sigma-Aldrich) solution precooled in an ice bath. The drug/surfactant solution was placed in an ice bath and the sample sonicated using a Cole Parmer Ultrasonic Processor (Vernon Hills, IL) at 50\% amplitude for 10 minutes. Particle size was determined by dynamic light scattering using a Zetasizer. The sonication time was increased at 2-minute intervals up to a maximum of 16 minutes total if the particle size was greater than $1.5 \mu \mathrm{M}$ The samples were characterized by light microscopy (20x magnification). The remaining suspension was vortexed and mixed at an adequate speed overnight at room temperature, then collected after 24 hours and centrifuged at a speed of $8100 \times \mathrm{g}$ for 20 minutes at $5^{\circ} \mathrm{C}$. After decanting the supernatant, the pellet was resuspended in $75 \mathrm{~mL}$ of filtered, reverse osmosis (RO) water and the samples centrifuged again at a speed of $8100 \times \mathrm{g}$ for 20 minutes at $5^{\circ} \mathrm{C}$. The pellet was resuspended in $1 \%$ mannitol in RO water (Sigma-Aldrich) solution for lyophilization. The particle size was again measured using a Zetasizer. Drug concentration in the final nanoART suspension was determined using HPLC as previously described. ${ }^{17}$

NanoART formulations were imaged by scanning electron microscopy as previously described..$^{14,17,22}$ Briefly, $10 \mu \mathrm{L}$ of nanosuspension was diluted in $1.5 \mathrm{~mL}$ of $0.2 \mu \mathrm{M}$ filtered double-distilled water. The diluted suspension was mixed, and a $50 \mu \mathrm{L}$ aliquot was transferred to a filtration apparatus (Swinnex 13 polypropylene filter holder, Millipore, Billerica, MA) assembled with a $0.2 \mu \mathrm{M}$ prewetted polycarbonate filter membrane (Nuclepore Track-Etched, Whatman International Ltd, Kent, ME). The entire solution volume was pulled through the filtration membrane by vacuum. The membrane was washed with $500 \mu \mathrm{L}$ of filtered double-distilled water. The membrane was allowed to dry for 24 hours, fixed to an aluminum pin stub using double-stick conductive carbon tape, and sputter coated with palladium (EMITECH K575X, Quorum Technologies, Ashford, Kent, UK). The samples were affixed to the specimen stub and imaged using a Hitachi S4700 Field Emission Scanning Electron Microscope (Hitachi High Technologies America, Inc, Schaumburg, IL). 


\section{Publish your work in this journal}

The International Journal of Nanomedicine is an international, peerreviewed journal focusing on the application of nanotechnology in diagnostics, therapeutics, and drug delivery systems throughout the biomedical field. This journal is indexed on PubMed Central, MedLine, CAS, SciSearch $\AA$, Current Contents ${ }^{\circledR} /$ Clinical Medicine,

Journal Citation Reports/Science Edition, EMBase, Scopus and the Elsevier Bibliographic databases. The manuscript management system is completely online and includes a very quick and fair peer-review system, which is all easy to use. Visit http://www.dovepress.com/ testimonials.php to read real quotes from published authors.

Submit your manuscript here: http://www.dovepress.com/international-journal-of-nanomedicine-journal 